\title{
The Importance of Employment for Recovery, in People with Severe Mental Illness
}

\author{
Nagesh Pai · Frances Dark • David Castle
}

Received: 4 October 2021 / Accepted: 4 October 2021 / Published online: 13 October 2021

(C) The Author(s), under exclusive licence to Springer Nature India Private Limited 2021

Psychiatric rehabilitation continues to focus on skills needed to live an independent life in the community. Current approaches recognise that patients' goals include normalisation, social integration and recovery [12]. Employment is a central pillar of personal identity in a civilised society. Since 1980, supported employment-and the Individual Placement and Support (IPS) model in particular-has grown and developed into a primary mainstay for those

\section{N. Pai $(\bowtie)$}

Graduate Medicine, School of Medicine, Faculty of

Science, Medicine and Health, University of Wollongong,

Wollongong, NSW, Australia

e-mail: nagesh@uow.edu.au

N. Pai

Illawarra Health and Medical Research Institute,

Wollongong, NSW, Australia

N. Pai

Illawarra Shoalhaven Local Health District, Wollongong,

NSW, Australia

\section{F. Dark}

Princess Alexandra Mental Health Service, Princess Alexandra Hospital, Woolloongabba, QLD, Australia e-mail: Frances.Dark@health.qld.gov.au

F. Dark

Queensland Health, Brisbane, QLD, Australia individuals with the most significant disabilities and has grown rapidly within the past decade, fuelled by the consumer empowerment and inclusion movements [3]. Supported employment is both cost-effective and an evidenced-based practice producing positive employment outcomes for a wide range of individuals with disabilities. People with severe mental illness who hold competitive jobs for a sustained period of time show benefits such as improved self-esteem and

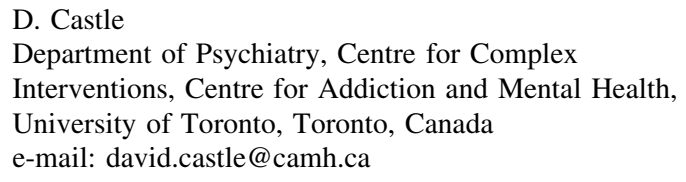


better symptom control, although by itself, enrolment in supported employment has no systematic impact on nonvocational outcomes, either on undesirable outcomes, such as rehospitalization, or on valued outcomes, such as improved quality of life [7]. In a review of the existing evidence relating to the impact of employment on recovery in people with schizophrenia, Charzynska et al. [2] conclude that employment carries "promising, but not conclusive, results in the improvement of quality of life, social functioning and other indicators of recovery" (pg. 407).

Given this, it is both sad and embarrassing that so many people with severe mental illnesses such as schizophrenia and related disorders remain unemployed or under-employed, in many countries. For example, in the Australian Study of High Impact Psychoses (SHIP) conducted in 2010, the rate of paid employment (last seven days) amongst people with a psychotic disorder was $19.2 \%$ : this was only marginally higher than in a study using the same methodology, conducted 13 years previously $(14.8 \%)$ [10, 11]. This was despite substantial expenditure from the Australian government into agencies tasked with getting people into employment. In a nation-wide Danish study with 35 years of follow-up, Hakulinen et al. [5] showed the odds ratio of unemployment associated with a diagnosis of schizophrenia between the ages of 15 and 25 years, was a staggering 39.4 (95\% CI 36.5-42.6). The story is similar in many jurisdictions, and likely to be exacerbated by employment restrictions and job losses world-wide, associated with the COVID-19 pandemic [4].

Why do so many people with schizophrenia remain outside the workforce? The answers are complex and multifactorial and the papers in this Special Issue hopefully elucidate some of them. One group of factors lie in issues to do with the illness burden associated severe mental illness, including often under-treated psychotic symptoms such as persecutory beliefs and distracting hallucinations, as well as residual negative symptoms and associated demoralisation. Psychiatric comorbidities such as depression and social anxiety disorder require assessment and specific therapeutic interventions, as they can be an added barrier to people with schizophrenia and related disorders seeking and retaining work: all too often these comorbidities are missed by clinicians as their associated behaviours such as social avoidance are considered part of the person's negative symptom set
[1]. Disorganisation symptoms require particular attention therapeutically but again are often not adequately addressed. Finally, cognitive problems associated with schizophrenia can impair vocational ability: the good news is that addressing cognitive problems directly can improve cognition is domains relevant to the workplace [9] and can have positive impacts on vocational outcomes [8]. There is also reason to be positive about the potential for the benefits for vocational outcomes of intervening early in the course of psychotic disorders: further work in this area is presented in this Special Issue.

Employment is key to social inclusion, and people with severe mental illness are still too often socially excluded on so many levels, and subject to stigma and negative attitudes regarding their contribution to society. The COVID-19 pandemic has been particularly difficult for people with a severe mental illness, with the requisite social distancing measures adding to their already often restricted lives [6]. The economic consequences of the pandemic, with projected job losses, are likely to further impact this group. We hope that the articles assembled in this Special Edition give some indications to the field as to some of the effective interventions that have helped people with schizophrenia and related disorders obtain and retain work. But what is more important is that such interventions are scaled up and made much more widely available to those in need, and as early in the course of illness as possible.

Funding The authors received no financial support for the research, authorship and publication of this article.

\section{Declarations}

Conflict of interest The authors have no conflict of interest to report.

\section{References}

1. Castle DJ, Buckley PF, Upthegrove R. Schizophrenia and psychiatric comorbidities. Oxford: Oxford University Press; 2021.

2. Charzynska K, Kucharska K, Mortimer A. Does employment promote the process of recovery from schizophrenia? A review of the existing evidence. Int J Occup Med Environ. 2015;28:407-18.

3. Drake RE. Employment and schizophrenia: Three innovative research approaches. Schizophr Bull. 2018;44:20-1. 
4. Fana M, Perez ST, Fernandez-Macias E. Employment impact of COVID-19 crisis: from short term effects to long term prospects. J Ind Bus Econ. 2020;47:391-410.

5. Hakulinen C, McGrath JJ, Timmerman A, et al. The association between early-onset schizophrenia with employment, education, and cohabitation status: a nationwide study with 35 years of follow-up. Soc Psychiatry Psychiatr Epidemiol. 2019;54:1343-51.

6. Kozloff N, Mulsant BH, Stergiopoulos V, Voineskos AN. The COVID-19 global pandemic: implications for people with schizophrenia and related disorders. Schizophr Bull. 2020;46:752-7.

7. Luciano A, Bond GR, Drake RE. Does employment alter the course and outcome of schizophrenia and other severe mental illness? A systematic review of longitudinal research. Schizophr Res. 2014;159:312-21.

8. McGurk SR, Drake RE, Xie H, et al. Cognitive predictors of work among Social Security Disability Insurance beneficiaries with psychiatric disorders enrolled in IPS supported employment. Schizophr Bull. 2018;44:32-7.
9. Miles A, Crosse C, Jenkins Z, et al. Employ your mind: a pilot evaluation of a program to help people with serious mental illness obtain and retain employment. Australas Psychiatry. 2021;29:57-62.

10. Morgan V, Waterreus A, Jablensky A, et al. People living with psychotic illness in 2010: the second Australian national survey of psychosis. Aust $\mathrm{N}$ Z J Psychiatry. 2012;46:735-52.

11. Waghorn G, Saha S, Harvey C, et al. 'Earning and learning' in those with psychotic disorders: the second Australian national survey of psychosis. Aust $\mathrm{N}$ Z J Psychiatry. 2012;46:774-85.

12. Whitley R, Drake RE. Recovery: a dimensional approach. Psychiatr Serv. 2010;61:1248-50.

Publisher's Note Springer Nature remains neutral with regard to jurisdictional claims in published maps and institutional affiliations. 